University of Wollongong

Research Online

Faculty of Informatics - Papers (Archive)

Faculty of Engineering and Information

Sciences

$5-9-2007$

\title{
Vendor Perceptions of How RFID can Minimize Product Shrinkage in the Retail Supply Chain
}

\author{
N. Huber \\ University of Wollongong, nickhuber@yahoo.com \\ Katina Michael \\ University of Wollongong, katina@uow.edu.au
}

Follow this and additional works at: https://ro.uow.edu.au/infopapers

Part of the Physical Sciences and Mathematics Commons

\section{Recommended Citation}

Huber, N. and Michael, Katina: Vendor Perceptions of How RFID can Minimize Product Shrinkage in the Retail Supply Chain 2007.

https://ro.uow.edu.au/infopapers/557

Research Online is the open access institutional repository for the University of Wollongong. For further information contact the UOW Library: research-pubs@uow.edu.au 


\title{
Vendor Perceptions of How RFID can Minimize Product Shrinkage in the Retail Supply Chain
}

\begin{abstract}
The objective of this paper is to investigate product shrinkage in the retail supply chain, and to consider how radio frequency identification (RFID) could act as a partial solution toward a retailer's loss prevention strategy. The research uses semi-structured interviews to collect data, and a qualitative content analysis to present the results. Given that the number of RFID deployments in the retail supply chain is limited, RFID vendors, resellers, and associations are instead used to gather the current value propositions. Representatives from nine Australian RFID vendors and associations were interviewed in August and September of 2006. The results indicate that RFID can be used to minimize losses in the supply chain significantly and particularly address product authentication issues. For RFID to be adopted as a loss prevention mechanism, however, organizations must have some visibility of what constitutes product shrinkage in their retail supply chain, and the resultant monetary losses ensuing. All too often, return on investment (ROI) calculations on the adoption of RFID in retail, is calculated only on known sources of product shrinkage, while unknown sources are unaccounted.
\end{abstract}

\section{Keywords}

radio frequency identification, product shrinkage, supply chain, vendors

\section{Disciplines}

Physical Sciences and Mathematics

\section{Publication Details}

This paper originally published as Huber, $\mathrm{N}$ and Michael, $\mathrm{K}$, Vendor Perceptions of How RFID can Minimize Product Shrinkage in the Retail Supply Chain, IEEE RFID Eurasia, Istanbul, Turkey, 5-6 September 2007, 1-6. 


\title{
Vendor Perceptions of How RFID can Minimize Product Shrinkage in the Retail Supply Chain
}

\author{
Nicholas Huber and Katina Michael, Senior Member, IEEE
}

\begin{abstract}
The objective of this paper is to investigate product shrinkage in the retail supply chain, and to consider how radio frequency identification (RFID) could act as a partial solution toward a retailer's loss prevention strategy. The research uses semi-structured interviews to collect data, and a qualitative content analysis to present the results. Given that the number of RFID deployments in the retail supply chain is limited, RFID vendors, resellers, and associations are instead used to gather the current value propositions. Representatives from nine Australian RFID vendors and associations were interviewed in August and September of 2006. The results indicate that RFID can be used to minimize losses in the supply chain significantly and particularly address product authentication issues. For RFID to be adopted as a loss prevention mechanism, however, organizations must have some visibility of what constitutes product shrinkage in their retail supply chain, and the resultant monetary losses ensuing. All too often, return on investment (ROI) calculations on the adoption of RFID in retail, is calculated only on known sources of product shrinkage, while unknown sources are unaccounted.
\end{abstract}

Index Terms - radio frequency identification, product shrinkage, supply chain, vendors

\section{INTRODUCTION}

This paper will determine the perceptions of RFID vendors and associations for the potential of RFID to minimize product shrinkage across the retail supply chain. Today, RFID is used for automatic toll collection on motor highways, tracking medicine vials in the pharmaceutical industry and accurately sorting luggage at international airports. However, the only application of anti-theft technology in major Australian retailers is Electronic Article Surveillance (EAS). Beyond the basic features of EAS, newer Generation-2 (Gen-2) RFID technologies facilitate the accurate tracking of goods across the supply chain giving the retailer unsurpassed 'visibility' of stock. Managing inventory using RFID offers a number of benefits that existing EAS and legacy barcode systems cannot achieve. Throughout this paper, employees from eleven different organizations offer their ideas and perceptions on various issues regarding RFID and product shrinkage. Real world examples are given on the application of RFID in industry to provide a grounded understanding for which lessons can be learned for the future adoption of the technology. An important question to be answered in this paper is; does RFID hold the potential to minimize product shrinkage across the retail supply chain?

\section{BACKGROUND OF RFID VENDORS AND ASSOCIATIONS}

The unit of analysis for this part of the study is RFID Vendors and Associations. A total of nine organizations formed this group, each of which was represented by an individual employee. RFID vendors included technology providers, manufacturers, system integrators and resellers of hardware and software, and the associations group included an RFID association and an RFID standards body. Employees selected for the study covered a broad range of expertise in the field of RFID. Employees involved in the study primarily included staff with managerial positions. However, technical staff, sales staff and consultants also took part in the study.

\section{METHODOLOGY}

The research was conducted using semi-structured interviews with RFID vendors in the Australian market. Ten different vendors and Associations were interviewed.

\section{A. Interviewees}

RFID Vendor 1 Business Development Manager

RFID Vendor 2 Systems Engineer

RFID Vendor 3 Managing Director

RFID Vendor 4 VP Marketing \& Business Development

RFID Vendor 5 Managing Director

RFID Vendor 6 Managing Director

RFID Vendor 7 National Sales Manager

RFID Association RFID Consultant

RFID Standards Standards Development Coordinator
Nicholas Huber is an Honors student at the School of Information Systems and Technology, Wollongong University, Australia 2522.

Katina Michael is a Senior Lecturer in the School of Information Systems and Technology, Faculty of Informatics, Wollongong University, Australia 2522 (corresponding author: 61242213937; fax: 61242214170; katina@uow.edu.au). 


\section{B. Questions}

- Determine the interviewee's job title and their role and responsibilities

- Gain an understanding of their experience in their given industry

- Gain an understanding of their experience with RFID technology

- Identify the contributing factors to product shrinkage in retail

- Identify items that constitute product shrinkage

- Identify areas where product shrinkage occurs in the supply chain

- Specify where product shrinkage occurs in the supply chain

- Identify characteristics of the organization's customer-base

- Discover the main drivers to adopt an RFID system

- Discover the benefits of RFID as part of a retail supply chain

- Discover the barriers to RFID adoption in the Australian retail industry

- Investigate the possibility for RFID to minimize product shrinkage

- Determine the advantages that Gen-2 RFID systems have over the well- established barcode (legacy systems) perceived by the retailer

- Identify standards used by the organization

- Ascertain the organization's view on source-tagging from the supplier

- Learn how RFID can be used with additional technologies

- Discover other perceived benefits of RFID besides

minimizing product shrinkage

\section{RFID VEndor Perceptions of Product ShrinKage}

When defining product shrinkage RFID Vendor (1) explained that it varies between industries, but generally it includes; lost, stolen (theft) and damaged goods. When asked about product shrinkage a typical response included these three sources. RFID Vendor (4) emphasized that "theft is the predominant contributor to product shrinkage." It was also interesting to discover that some vendors were unaware of all the sources that contribute to product shrinkage. This suggests the possibility that vendors are oblivious to the problems encountered by retailers; organizations which could represent a large portion of their customer base.

Nonetheless, the Systems Engineer (RFID Vendor 2) was well informed on sources that contribute to product shrinkage, as he had previously worked in the retail industry. He provided a detailed understanding of the contributing sources to product shrinkage including:

theft, damaged goods, overdue items, past due date items. Since I got into IT, I have been doing a lot in the supply chain, so there is obviously damage within transit, misrouted or otherwise lost goods throughout the supply chain, incorrect numbers shipped, over shipped, under stocked, all that kind of stuff constitutes product shrinkage (RFID Vendor 2).
When the Managing Director (RFID Vendor 3) was asked what product shrinkage was he simply replied "[a]nything that represents a loss of a physical asset." A physical asset in the retail industry generally covers consumer-based products and the reusable pallets and containers which carry them. Physical assets can be unaccounted for at any point across the supply chain. RFID Vendor (3) further explained that main contributors to product shrinkage have not been accurately determined:

I don't know and I don't believe anybody knows. I tried to get figures out of the New South Wales Police on fraud, they didn't know; the New South Wales Retailers Association, they didn't know... the real issue is there hasn't really been a way to measure it. And one of the things that RFID can do is actually assist you in measuring it.

The most significant part of this quote resides in the fact that there is no way to measure product shrinkage. RFID Vendor (3) may have recognized RFID as a technology which can be used to accurately measure the contributing sources of product shrinkage, yet in what ways can RFID minimize product shrinkage?

\section{Minimizing Product ShrinKage USING RFID}

RFID technologies were considered by most RFID vendors and associations as a solution to product shrinkage in the retail industry. As proposed by RFID Vendor (2) the main drivers for the adoption of RFID in the retail industry is the technologies potential to minimize shrinkage and to improve supply chain efficiencies. Not all the benefits of RFID within a retail environment have been realized by vendors. There are a number of techniques and applications that give this technology the ability to minimize product shrinkage across the retail supply chain (Figure 1).

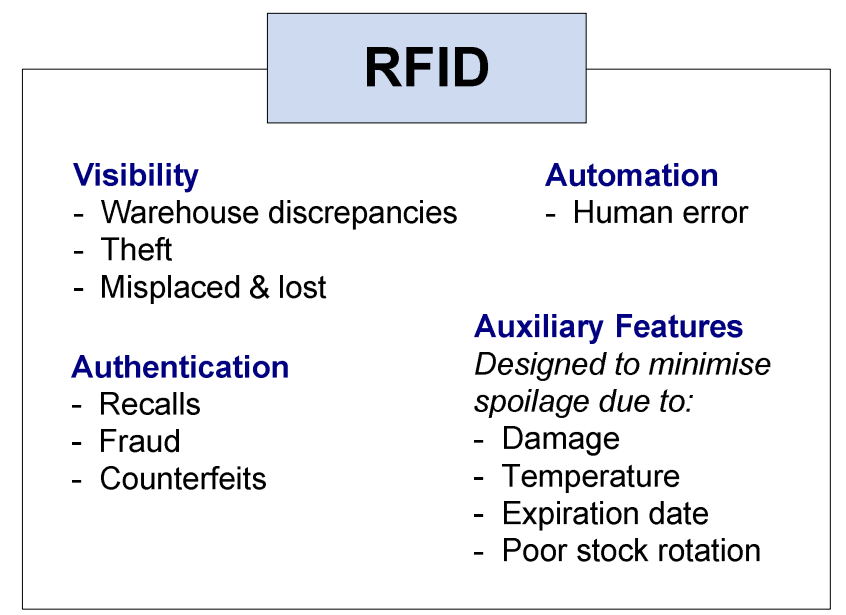

Figure 1 RFID as a means to minimize product shrinkage 


\section{A. Visibility}

It was discovered that one of the main drivers pushing RFID in the industry was its ability to provide visibility across the entire supply chain. Visibility is described as an organization's ability to accurately track and observe the movements of products across the supply chain [1], [2]. As stated by RFID Vendor (6), "[t]he whole thing's about getting visibility in the supply chain". Gaining visibility across the supply chain allows a retailer to collect accurate information to support the decision making process [3]. Furthermore, the visibility of products throughout the supply chain process increases the likelihood that a product will reach its destination; the customer. RFID Vendor (4) offered a scenario to demonstrate this theory: "[1]et's say you build 100 items, so if RFID saves shrinkage you'll have 100 items to sell. If you know where the 100 items are you can actually sell those 100 items and allows you to hold less stock." This example illustrates the basic, yet fundamental concept of visibility provided by an RFID solution. Further supporting this idea, Garfinkel and Rosenberg [4], also recognizes the reality, that if a retailer cannot find a product, they cannot sell it. If a retailer has the ability to find and pinpoint the exact location of its products, it can potentially minimize:

1. warehouse discrepancies;

2. theft; and

3. misplaced and lost products.

It is important to realize that these three factors are major contributors to product shrinkage in the retail industry. The automatic identification (auto-ID) of products using RFID has the potential to accurately manage stock across the retail supply chain, effectively reducing the chances of misrouted or misplaced products.

\section{1) Warehouse Discrepancies}

The continuous demand from customers in the retail industry requires a constant flow of goods from the point of manufacture to the retail outlet. Retailers must successfully coordinate timely and effective responses to customer demand. As suggested by Pisello [5], RFID can support this process by validating the accuracy of deliveries and shipments. Inaccuracies which occur in a retail supply chain are commonly called discrepancies. A discrepancy represents any form of an inaccuracy in a delivery. For example, a retail outlet may order 1000 products from the warehouse and only receive 980 products. Due to the large number of cartons, the back-dock attendant is not required to scan each individual box using a barcode scanner. Thus, 20 cartons are unaccounted for and subsequently, a discrepancy occurs. As suggested by the RFID consultant from the RFID Association:

[a] retailer wants to minimize mistakes. When you are at the dock and you receive your deliveries you have to check ever single item on the pallet, right? Well how about you just scan the pallet and the pallet itself will just tell you what's inside. So you don't need to undo the pallet at all.
Apart from its ability to minimize human intervention and labor costs, RFID can automatically identify products as they leave a delivery vehicle. Tagged products that pass by a number of RFID antennas in a gateway arrangement can be automatically counted. During this process, warehouse personnel can be alerted to any errors that may occur and finally verify a delivery ready for dispatch. Using RFID, a retailer has the ability to minimize warehouse discrepancies by accurately confirming a delivery vehicle's load. It is anticipated that reducing errors in preparing and receiving deliveries from the distribution centre to the retail outlet will result in a reduction in overall product shrinkage levels.

\section{2) Theft}

The application of Electronic Article Surveillance (EAS) technology has been widely embraced by retailers as an antitheft mechanism. EAS is a closed-loop system with the sole purpose to deter thieves (RFID Vendor 2). Furthermore, RFID Vendor (3) agreed that EAS is not a total solution but a deterrent. To "get a total solution you actually need to track everything from the point of manufacture, you need to tag it at the point of manufacture... and then integrate it throughout the entire supply chain" (RFID Vendor 3). Gen-2 RFID technologies offer advantages that surpass a simple EAS antitheft configuration.

As stated by RFID Vendor (7) using RFID to combat sources of shrinkage "you've got the ability to keep track of products in and out of the store." Using RFID to actively monitor products in a retail outlet can potentially assist in preventing theft [4]. In this particular application a retailer can detect abnormal behavior, such as twenty razor blade packages being removed from the shelf at once [6]. Using a notification system, employees could be alerted to watch the individual who removed the products ensuring that the products are paid for before the shopper leaves the store [6]. Monitoring products using RFID coupled with a notification system in a supermarket is not the only instance were RFID can provide visibility by actively tracking products.

\section{3) Misplaced and Lost Products}

Products can also be monitored using RFID throughout the entire retail supply chain. Firstly, the definitions of misplaced and lost products within a retail setting are to be defined. Products that have been 'misplaced' have generally been moved to a misallocated section of a warehouse or retail outlet. However, if a product is not located within a certain timeframe, its status is said to be 'lost' or unaccounted for. Unrecovered products are typically assumed to be lost and as a result are added towards the total of unknown product shrinkage.

A product that is believed to be out of stock or unavailable does not necessarily occur because products have been sold or stolen; products are also commonly misplaced. RFID can assist by tracking and tracing products at any point across the supply chain. According to RFID Vendor (1), a retailer using 
RFID has the ability to "track and trace a particular product at item-level through the whole supply chain process." If a retailer can accurately monitor stock throughout the supply chain products are less likely to go missing in the first place.

\section{B. Authentication}

RFID can also offer value by minimizing product shrinkage in its ability to rapidly authenticate a tagged object. A retailer can take advantage of this feature by scrutinizing tagged products at any point across the supply chain. Authentication can be used to locate defective products during recalls, detect possible acts of fraud and identify counterfeit products.

\section{1) Recalls}

Product recalls are considered to be one of the primary motivators to adopt RFID. According to RFID Vendor (1), "product recalls cost millions and millions of dollars". Products in the retail industry (especially food products) need to comply with certain safety criteria. If these criteria are not met products are assumed to be defective and unfit for consumption. When a product line is recalled large quantities of stock need to be identified, gathered and disposed of. Unfortunately, not all goods identified in this process are actually defective. In fact, extortion attempts against large corporations which target popular products in most cases do not pose a threat to the consumer. However, in this situation the manufacturer or retailer has no alternative but to dispose of the majority, if not all products that are said to be defective.

The ability to authenticate a product using RFID can minimize the overall impact of product recalls and extortion attempts. RFID is gaining much momentum in the pharmaceutical industry as a tool to manage recalls (RFID Vendor 1) [7]. Using an RFID scanning device retail employees can accurately locate a desired product and establish whether it is subject to recall. From a safety perspective, the pharmaceutical and retail industries together rely on the overall quality of their products. The pharmaceutical industry may be investing in RFID technologies to minimize the impact of product recalls, but why have we not seen Australian retailers adopt RFID to minimize this issue as well?

\section{2) Fraud}

In the retail industry, fraud includes refunding products to an alternative store (other than the place of purchase) to receive a higher return. As described by RFID Vendor (3) retail fraud also involves the act of placing foreign barcodes on products as to ensure that they scan at a lower price. As a barcode can essentially be an adhesive label, barcodes are easy to reproduce (RFID Vendor 3) and fastened over a product's original barcode. As described by RFID Vendor (3), "nine times out of ten the checkout person wouldn't know." However, barcode fraud can also occur at any point across the supply chain. For instance, a third party supplier may dishonestly alter barcodes on a number of products included in a large delivery and being unaware of this a retailer could accept the delivery.

RFID can assist by authenticating a product's point of origin. If a product can be identified and confirmed as previously owned by a retailer, the products' value has a better chance of being retained by the retailer and not lost due to fraud. The issue of fraud is closely related to illegitimate product reproductions.

\section{3) Counterfeits}

The authenticity of goods is a great concern in the pharmaceutical industry (RFID Vendor, 1-4; Heinrich 2005). According to Heinrich [8], "[t]he Food and Drug Administration (FDA) mandate for pharmaceutical manufacturers to use RFID-tagged pill bottles was driven by the desired to eliminate the estimated 2 to 7 percent (approximately [US] \$30 billion) of counterfeit drugs sold each year." RFID is capable of the mass serialization to track and trace individually tagged products. Serial numbers is a fundamental requirement for a successful anti-counterfeit solution [6]. In the retail industry the application of RFID for anti-counterfeiting purposes is most likely to include clothing and other high-end products.

Electronics, designer clothing brands and other high value items, often targeted by fraudsters, are ideal items for anticounterfeit technologies. The Benetton Group initiative in the United States required clothing items to be embedded with an RFID tag to detect counterfeit products (RFID Vendor 7). In this application, clothes can be assumed counterfeit if the garment is found without a tag or the tag contains an invalid item code [9]. In this particular case, RFID holds the potential to combat criminal operations. In addition, it can reduce the distribution of goods throughout the 'grey market' and ultimately, prevent the sale of counterfeit products to consumers. The anti-counterfeiting capability of RFID can minimize product shrinkage by eliminating the possibility of a retailer unknowingly investing in counterfeit products.

\section{Automation}

Fischer and Green [10] identify "bad checks" as an activity that contributes to loss experienced by retailers. Checking products using a barcode system involves manually scanning a product's barcode at any point across the supply chain. A bad check occurs when a product fails to be recognized, due to human intervention or a barcode error. However, RFID offers the potential to minimize these errors.

The Electronic Product Code (EPC) standard for data storage on an RFID tag is designed for the automatic identification of products across the retail supply chain. An EPC code identifies the manufacturer, product category and the individual item [11] [12]. Automatic identification of such data is designed to reduce errors incurred by human intervention. 


\section{1) Human Error}

RFID facilitates automatic inventory auditing [13]. Auditing, more commonly known in retail as stock take is the process of determining stock levels. Stock take generally involves the use of barcode scanners to identify products, which are then manually counted by hand. Miscalculated products are most likely linked to human errors which then add to overall product shrinkage levels (RFID Vendor 6). However, stocktaking can be completed quickly and accurately using an RFID enabled handheld scanner [13]. Using the EPC convention for data storage a product can be individually identified and the total number of products recorded. According to RFID Vendor (2), RFID can streamline supply chain processes and remove the necessity for personnel to assist with tedious operations; "zero human intervention operation" (OHIO). A system which requires minimal physical manipulation of stock level data is just one benefit of RFID adoption within a retail environment. However, reducing errors due to human intervention is not the only benefit where RFID can minimize product shrinkage.

\section{Auxiliary Applications}

In a retail environment products are generally spoiled if they are: damaged, broken, unsealed, exposed to incorrect temperatures or out of date. Products that have been spoiled are commonly discarded and hence, contribute to large quantities of product shrinkage. RFID can minimize product shrinkage using the following auxiliary features.

\section{1) Damaged Products}

An interesting issue raised by the RFID Association was RFID's ability to gather information about a product and categorize it accordingly. For example, a retailer could implement an RFID reader to record damaged stock at the opening of a waste deposit. The retailer would then be able to keep an accurate record of damaged goods. In this application RFID does not reduce damaged stock, but it does record it. As suggested by the RFID Association:

They might not be able to fix the problem, but they are going to categorize it; this is stolen, this is broken and then they could get rebates from their suppliers. If they have information about where and why the product is part of shrinkage, then maybe they can get dollars back.

If a retailer can record damage products they can claim for credit through insurance or through other formal agreements with their suppliers. This information could also be made available to manufacturers interested in a regularly damaged product. Improvements could be made to a particular product or its packaging to resist certain elements on its way to the retail outlet and onto the shelf.

In addition, as suggested by RFID Vendor (2) transporting goods using RFID simply removes the human interaction as products are scanned automatically. Minimal handling of stock by personnel results in a further reduction in the likelihood that products are accidentally dropped or mishandled. "The big cost for most retailers is the amount of handling that occurs at the manufacturer through distribution centre to the retail store" (RFID Vendor 7). A retailer can further reduce spoilage of products by closely monitoring temperature.

\section{2) Temperature}

In the retail industry, it is imperative that perishable products remain within a fixed temperature range across the entire supply chain. Perishable products in-transit are vulnerable to incorrect temperature exposure. For example, frozen seafood awaiting dispatch at a distribution centre may be unintentionally left in direct sunlight for an extended period of time. In addition, large prime movers (delivery vehicles) travel great distances and take multiple routes during transportation. During this process, products are vulnerable to fluctuating temperatures.

According to RFID Vendor (2), a temperature sensor can be attached as an additional device on an RFID tag. Sensors can monitor temperature levels in real-time [14] or at various intervals. Tags for this purpose can be attached to a shipping container, a vehicle or an individual product. As RFID tags can function at temperatures ranging from $-40^{\circ} \mathrm{C}$ to $204^{\circ} \mathrm{C}$ [4], they are suitable for cold and frozen storage and logistics. It is in this particular application that RFID tags can eliminate or reduce product spoilage [15].

In the not too distant future RFID tags will offer seamless product temperature records from point of manufacture to the time of purchase [14]. Using this form of RFID application both the retailer and the customer can be reassured of a product's temperature throughout the entire supply chain process.

\section{3) Expiration Date and Stock Rotation}

Monitoring expiration dates of a retailer's complete inventory list is a challenging task. Currently, products that are found to be expired are disposed of. According to Symbol Technologies [2], RFID can be used by a retailer to monitor product expiration. If a retailer can immediately determine when a product is due to expire, products can be strategically placed or re-priced for quick sales.

Existing technology utilized by retailers does not allow data such as expiration dates to be monitored. Advances in RFID could ensure the retailer is constantly aware of products that are approaching expiration. Employees could be notified in real-time if the product should be moved to the front of the shelf. This would drastically reduce the human intervention required in recognizing items that are soon to expire.

A product's expiration date is closely linked to the practice of stock rotation in retail. Stock rotation involves the routine of physically moving products from the back of the shelf to the first row on display to the customer. This basic routine plays a role in minimizing product shrinkage. 


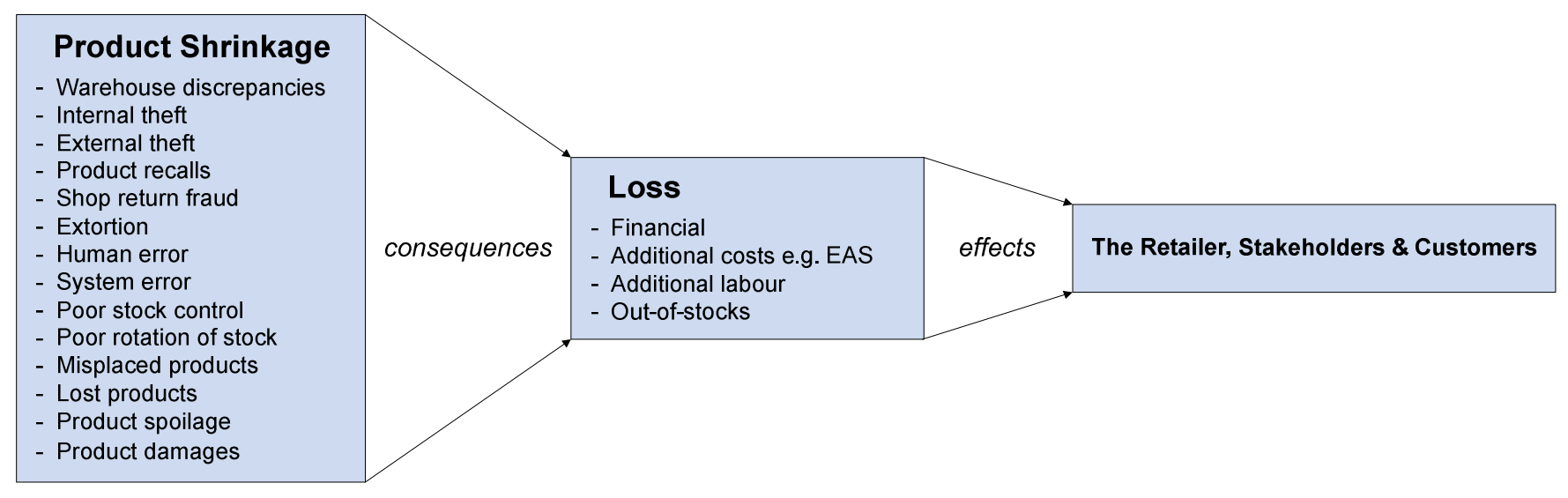

Figure 2. The cascading effect of product shrinkage

\section{CONCLUSION}

The RFID vendors and associations involved in this study acknowledged the potential of RFID to minimize product shrinkage across the supply chain. In most cases the interviewees were aware of the issue of product shrinkage, yet they were unaware of its main contributing factors. This unfamiliarity suggests that their knowledge of their customer base (consisting of retailers) is not as extensive as expected. It was discovered that one of the main drivers pushing the adoption of RFID in the retail industry was its ability to provide 'visibility' of stock, improve efficiencies and potentially minimize product shrinkage across the supply chain. Visibility was a key finding to the prevention of warehouse discrepancies, theft and the likelihood of products being misplaced or lost (figure 2). The technology's capacity to authenticate products during recalls, acts of fraud and in identifying counterfeits was also found to be of benefit. The automation of supply chain processes recognized RFID as being a means to dramatically minimize human errors. Finally, RFID's auxiliary features allow a retailer to minimize loss by recording products as 'known damaged', maintaining correct temperatures in storage and during transportation, manage the expiration dates of products and rotate stock effectively. All these characteristics were recognized by RFID vendors and associations, accompanied by supporting academic papers and trade sources, as being characteristics of RFID with a potential to minimize product shrinkage across the retail supply chain. It is expected that the adoption of RFID for visibility throughout the supply chain, would in most cases, reveal a far greater detail and size of product shrinkage occurring than most loss prevention managers are currently estimating.

\section{REFERENCES}

[1] Symbol Technologies, Business Benefits from Radio Frequency Identification (RFID), Technical Brief, Sep, 2004, pp. 1-6.

[2] Symbol Technologies, Understanding Gen-2: What is it, How will you Benefit and Criteria for Vendor Assessment, White Paper, Jan, 2006, pp. 1-8.

[3] Checkpoint Systems (2003) Retail News: Technology News for Loss Prevention and Supply Chain Management, Dec, [Online], Available: http://www.checkpointsystems.com/ download.aspx? page=stsuccess\&dir=d\&file=rn1_5_04.pdf [Last Accessed: 10 October 2006]

[4] S. Garfinkel and B. Rosenberg, RFID Applications, Security and Privacy, Addison-Wesley, Upper Saddle River, 2005.

[5] Pisello, T. (2006) The ROI of RFID in the Supply Chain, RFID Journal, 21 Aug, [Online], Available: http://www.rfidjournal.com/ article/articleprint/2602/-1/128/ [Last Accessed: 15 September 2006]

[6] Forcinio, H. (2003) Prevent Losses with RFID, Managing Automation, Jan, [Online], Available: http://www.managing automation.com/maonline/magazine/read/view/Prevent_L Losses _with_RFID_3176 [Last Accessed: 10 October 2006]

[7] IBM Corporation (2006) RFID Solution for Pharmaceutical Track and Trace, [Online], Available: http://www-03.ibm.com/solutions/ businesssolutions/sensors/ doc/content/sol ution/1624269129.html [Last Accessed: 10 October 2006]

[8] C. Heinrich, RFID and Beyond: Growing Your Business Through Real World Awareness, Wiley Publishing Inc., Indianapolis, 2005, p. 176.

[9] S. Lahiri, RFID Sourcebook, IBM Press, Pearson Education, Upper Saddle River, 2006.

[10] R.J. and G. Green, Introduction to Security: Seventh Edition, Butterworth-Heinemann, Burlington, 2004, p. 345.

[11] R.A. Kleist, T.A. Chapman, D.A. Sakai, and B.S. Jarvis, RFID Labeling: Smart Labeling Concepts and Applications for the Consumer Packaged Goods Supply Chain, 2nd Edition, Printronix Inc., Irvine, 2005.

[12] R. Want, "An Introduction to RFID Technology, Pervasive Computing", IEEE, Vol. 5, Iss. 1, Jan-March, 2006, pp. 25-33.

[13] M.M. Ollivier, "RFID: a new solution technology for security problems," European Convention on Security and Detection, 16-18 May, 1995, pp. 234-238.

[14] Smith, J.N. (2005) Specialized Logistics for a Longer Perishable Supply Chain, World Trade Magazine, [Online] Available: www.pressroom.ups.com/staticfiles/articles/456.pdf [Last Accessed: 20 October 2006]

[15] RFID Association of Australian (2006) What is RFID used for?, [Online], Available: http://www.rfidaa.org/about-rfid [Last Accessed: 20 October 2006]. 